\title{
Additive Manufacturing Technologies Used for Processing Polymers: Current Status and Potential Application in Prosthetic Dentistry
}

\author{
Revilla-León, Marta ; Özcan, Mutlu
}

\begin{abstract}
There are 7 categories of additive manufacturing (AM) technologies, and a wide variety of materials can be used to build a CAD 3D object. The present article reviews the main AM processes for polymers for dental applications: stereolithography (SLA), digital light processing (DLP), material jetting (MJ), and material extrusion (ME). The manufacturing process, accuracy, and precision of these methods will be reviewed, as well as their prosthodontic applications.
\end{abstract}

DOI: https://doi.org/10.1111/jopr.12801

Posted at the Zurich Open Repository and Archive, University of Zurich

ZORA URL: https://doi.org/10.5167/uzh-184749

Journal Article

Accepted Version

Originally published at:

Revilla-León, Marta; Özcan, Mutlu (2019). Additive Manufacturing Technologies Used for Processing Polymers: Current Status and Potential Application in Prosthetic Dentistry. Journal of Prosthodontics, 28(2):146-158.

DOI: https://doi.org/10.1111/jopr.12801 


\section{TITLE}

Additive manufacturing technologies used for processing polymers: Current status and potential application in prosthetic dentistry.

Marta Revilla-León DDS, MSD, a Mutlu Özcan DDS, DMD, PhDь

aAffiliate Faculty Graduate Prosthodontics, University of Washington, Seattle, WA and researcher at Revilla Research Center, Madrid, Spain.

bProfessor and Head, Dental Materials Unit, Center for Dental and Oral Medicine, University of Zürich, Switzerland. 


\begin{abstract}
There are 7 categories for the additive manufacturing (AM) technologies and a wide variety of materials that can be used to build a computer aided designed (CAD) 3Dimensional (3D) object. The present article reviews the main AM processes for polymers for dental applications: stereolithography (SLA), direct light processing (DLP), material jetting (MJ) and material extrusion (ME). The manufacturing process, accuracy and precision of these methods will be reviewed, as well as, their prosthodontic applications.
\end{abstract}

Keywords: 3D printing, Additive manufacturing technologies, Direct light processing, Fused deposition modelling, Material extrusion, Material jetting, Multijet printing, Prosthodontics, Stereolitography.

\title{
INTRODUCTION
}

Additive manufacturing (AM) technologies has tremendously developed in the last years, allowing their integration on the digital workflow for prosthetic applications. AM are the computer aided manufacturing (CAM) technologies that consists on the fabrication of an object layer-by-layer building up process.1 The American Section of the International Association for Testing Materials (ASTM) international standard organization develops voluntary consensus of technical standards for a wide range of materials, products, systems, and services. The ASTM committee F42 on AM technologies has determined seven AM categories: stereolithography (SLA), material jetting (MJ), material extrusion (ME) or fused deposition modelling (FDM), binder jetting, powder bed fusion (PBF), sheet lamination and direct energy deposition.1 The current article review the main AM technologies used for polymer printing for dental applications. 


\section{Stereolithography (SLA)}

The SLA technology was conceived by Chuck W. Hull,2-4 where the building platform is immersed in a liquid resin that is polymerized by an ultraviolet laser. The laser draws a cross-section of the object to form each layer. After the layer is polymerized, the building platform descends by a distance equal to the layer thickness, allowing uncured resin to cover the previous layer. This process is repeated a number of times until the printed object is built.2-4 Almost at the same time of Prof. Hull research, Prof. André prepared different patent for SLA technology in France.5,6

Laser based SLA 3D printing uses a UV laser to trace out the cross-sections of the object. The laser is focused using a set of lenses and then reflected off of two motorized scanning mirrors (galvanometer). The scanning mirror directs the precise laser beam at the reservoir of UV sensitive resin to cure the layer (Fig. 1). The depth of cure, which ultimately determines the z-axis resolution, is controlled by the photoinitiator and the irradiant exposure conditions (wavelength, power and exposure time/velocity) as well as any dyes, pigments or other added UV absorbers.7-9

Generally, on the SLA process the layer thickness depends on the model of the printer which could range between 15 to $150 \mu \mathrm{m}$ with a superficial roughness of approximately 35-40 $\mu \mathrm{m}$ RA.10 The wavelength range of the UV light that polymerized the raw material depends on the printer, but it can range from 200 to $500 \mathrm{~nm}$ (Table 1).

One advantage of SLA technology is the temperature resistance and freedom of complex geometries that can print; whereas the main limitation is the necessity of support structures to manufacture objects that consumes additional material and increase the production and post-processing time.11 


\section{Direct Light Processing (DLP)}

Larry Hornbeck of Texas Instruments created the technology for Digital Light Processing (DLP) in 1987.12 The DLP AM is very similar to SLA technology, as it is considering the same AM category by the ASTM.1

The main difference between the SLA and DLP is the light source, where the image is created by and arc lamp or by a microscopically small mirrors laid out in a matrix on a semiconductor chip, known as a Digital Micromirror Device (DMD). Each mirror represents one or more pixels in the projected image. The number of mirrors corresponds to the resolution of the projected image. 13

A vat of liquid photopolymer is exposed to light from a projector under safelight conditions. The DLP projector displays the image of the 3D model onto the liquid photopolymer. In this system the physical object is pulled up from the liquid resin, rather than down and further into the liquid photopolymeric system. The radiation passes through a UV transparent window.13 The process is repeated until the $3 \mathrm{D}$ object is built.12,13

\section{Material Jetting (MJ, PP)}

The material jetting technology could be also called Polyjet Printing (PP) where a liquid resin is selectively jetted out of hundreds of nozzles and polymerized with ultraviolet light.7 The UV-curable polymers are applied only where desired for the virtual design and, since multiple print nozzles can be used, the supporting material is co-deposited. Moreover, different variations in color or building materials with different properties can be designated including the formation or structures with spatially graded properties (Fig. 2). 15,16 


\section{Material Extrusion (ME, FDM)}

Also called Fused Deposition Modelling (FDM). It is a 3D printing method based on the extrusion of a thermoplastic material, material is drawn through a nozzle, where it is heated and is then deposited layer by layer. The nozzle can move horizontally and a platform moves up and down vertically after each new layer is deposited (Fig. 3).17 FDM was first developed by Stratasys, founded by Scott Crump in the early 1990's.18 The patents originally held by Stratasys have expired-resulting in dozens of FDM brands for the consumer market.

The FDM process has many factors that influence the final model quality but has great potential and viability when these factors are controlled successfully. Whilst FDM is similar to all other 3D printing processes, as it builds layer by layer, it varies in the fact that material is added through a nozzle under constant pressure and in a continuous stream. This pressure must be kept steady and at a constant speed to enable accurate results.19 Material layers can be bonded by temperature control or through the use of chemical agents.

Additionally, the nozzle which deposits material will always have a radius, as it is not possible to make a perfectly square nozzle and this will affect the final quality of the printed object.20 Accuracy and speed are low when compared to other processes and the quality of the final model is limited to material nozzle thickness.21 When using the process for components where a high tolerance must be achieved, gravity and surface tension must be accounted for.19 Typical layer thickness varies from $0.178 \mathrm{~mm}$ to $0.356 \mathrm{~mm} .22$

\section{Manufacturing Process}


The complete process of manufacturing an object with a 3D printer involves the following sequence: data acquisition, data processing, additive fabrication and post-processing procedures.15,16

- Data acquisition can be performed by either non-contact or contact scanning devices. The most common techniques used are computerized tomography $(\mathrm{CT})$, cone beam computed tomography (CBCT), magnetic resonance imaging (MRI) and laser digitizing (extraoral or intraoral scanning devices), (Fig. 4AB).

- Data processing involves the virtual design of the object using a specific CAD software (Fig. 5AB). When the design of the object is completed, the stereolithography (STL) file is imported on the printer software where the specifying the build variables and parameters for slicing and adding the support structures to generate the information needed for control the 3D printer (Fig. $6 \mathrm{AB})$.

- Additive fabrication means to build the object using the slice file on the 3D printer (Fig. 7AB).

- Post-processing, cleaning the object and post-curing to complete the polymerize process (Fig. 7C-F). Each technology and printer will have its own postprocessing recommendations provided by the manufacturer.

\section{Resolution, accuracy and repeatability of SLA, DLP, MJ and FDM}

The distinction between resolution, precision and trueness needs to be clarified. Resolution is the finest or smallest feature that the $3 \mathrm{D}$ printer can reproduce which is specific for each technology and printer (Table 1). The resolution of a 3D printer should be defined on each $\mathrm{x}, \mathrm{y}$ and $\mathrm{z}$-axes in $\mu \mathrm{m}$ or Dots Per Inch (DPI), where z-axis corresponds normally to the layer thickness. Precision or repeatability is the ability of a 3D printer to 
manufacture objects with exact same 3D-dimensions or how close repeated printed objects are to each other. Trueness refers to the discrepancy between the printed object and actual dimensions of the desired object. 23

In the dental digital workflow, discrepancies can be incorporated on each step. Moreover, the technology selected, the 3D printer used as well as the material chosen for the additive manufacturing of the desired object (Table 1,2). Not all the printers that manufacture an object with the same technology present the same resolution capabilities; so, each printer has a determined resolution which is provided by their manufacturer. Moreover, each material has its own activation range wavelength, power and exposition time for their manufacturing on 3D printers; so, not all the AM materials are compatible with all the AM printers. Furthermore, the manufacturer's post-processing procedures need to be carried out carefully to avoid further distortions of the printed object.

Different factors can affect the accuracy (precision and trueness) of the printed object as laser speed, intensity, angle and building direction,22-27 number of layers,22 software,27 shrinkage between layers, 25 amount of supportive material 24 and postprocessing procedures.

Because of the disparities on the protocols, technology selected and parameters of the printers and the $3 \mathrm{D}$ polymer printed material used, it is very difficult to compare the results obtained on different studies.

Alharbi et al25 evaluated the effect on the printing building direction on the mechanical properties of a cylinder-shaped hybrid composite resin printed specimens. Vertically printed specimens with the layers oriented perpendicular to load direction significantly presented a higher compressive strength than horizontally printed specimens with the layers oriented parallel to load direction. 
Brain at al26 studied the manufacturing tolerance of four polymers AM printers (Formiga P110 from EOS, Projet MP 3510 from 3D Systems, Objet 30 and Object Eden from Stratasys) following the manufacturer's parameters. Two geometries were analysed. The AM material was selected based on the print resolution, specification of the production unit, software and the manufacturing time; only 2 of the 4 printers used the same AM material. Differences on the production tolerance were founded between the different printers and technologies analysed. The results showed and accuracy from -61 to $92 \mu \mathrm{m}$.

Ide et al27 analysed the capacity of the 3D printers to reproduce acute angles $\left(60^{\circ}\right.$, $45^{\circ}, 30^{\circ}, 20^{\circ}, 10^{\circ}$ and $5^{\circ}$ ) considering the building printing direction on a six triangular prism-shaped specimens using one polyjet and two FDM AM printers. Each printer used different AM material. They concluded that the dimension production tolerance of the printers of geometry analysed was less than $1.00 \mathrm{~mm}$ in all the $\mathrm{x}, \mathrm{y}$ and $\mathrm{z}$-axes, but the acute angles could not be reproduced precisely.

\section{Prosthodontic applications}

There are a wide variety of available polymers for prosthodontics applications of 3D printing likewise printed casts (diagnostic casts, definitive casts for tooth-borne prostheses and definitive casts for implant-borne prostheses), complete dentures, printed castable patterns for casted or pressed restorations or custom impression trays.

\section{Printed Casts}

One of the first applications of the AM technologies was the materialization of the digital impression in order to obtain printed casts for diagnostic purposes or definitive casts to deliver a tooth-borne or implant-borne fixed dental prostheses (FDP), (Fig. 8A). 
For the prosthodontic applications, where a digital impression is made, the most reasonable workflow includes two options for the manufacturing of the tooth-borne FDP: a milled monolithic full-contour restoration or a milled or additive manufacturing framework with a posterior ceramic application. On the first option, the marginal and internal fit, contact point and occlusal contact are defined on the STL file of the virtual design of the restoration, which its accuracy is the accumulation of the distortion from the digital impression, the parameters determined on the design software and the CAM processes to manufacture the restoration. In this case, the fabrication of the definitive cast can be avoided. On the other hand, on the second option only the marginal and internal fit is determined on the virtual design on the restoration; so, the manufacturing of the definitive cast is a necessary step to finish the restoration for the ceramic application where the contact point and occlusal contact will be created.

The extraoral digitalization of the diagnostic cast for orthodontic purposes is widely analysed on the literature.28-32 The studies reported that the digital models are as reliable as traditional plaster casts, with high accuracy, reliability, and reproducibility. However, the reported limitation of these extraoral digitalization is the landmark identification, instead of the measuring system or the software employed. 31,32

The intraoral digitalization of the patient's mouth and the additive manufacturing of the Stereolithographic Tessellation Language (STL) file obtained has been also evaluated.33-37 In 2014, Patzelt et al34 digitalized a dental model with a laboratory scanner as a reference and three intraoral scanners (Lava Chairside Oral Scanner C.O.S, CEREC AC Bluecam and iTero) from which a 3D printed (SLA technology for the LAVA C.O.S and CEREC Bluecam digital impression) or milled (for the iTero digital impression) casts were manufactured and re-scanned with the same laboratory scanner. Using a specific CAD software, the casts were superimposed to analysed the distortion. The trueness 
values reported for Lava C.O.S., iTero and CEREC AC Bluecam were 38, 49 and 332.9 $\mu \mathrm{m}$, respectively; and the precision values were 38, 40 and $99 \mu \mathrm{m}$, respectively. Moreover, the SLA-based casts presented a higher accuracy than milled casts.

Hazeveld et al36 investigated the accuracy and reproducibility of physical dental casts reconstructed from digital data by three different AM techniques: DLP, MJ and a powder based polymer (PBP) printer. The mean systematic differences for the measurements of the height of the clinical crowns were 40, -20 and $40 \mu \mathrm{m}$ for the DLP, MJ and PBP printed casts respectively. For the width of the teeth, the mean systematic differences were $-50,80$ and $-50 \mu \mathrm{m}$ for the DLP, MJ and PBP groups. The dental models manufactured with the CAM tested could be a reliable option for orthodontic purposes, however it may be not enough accuracy for prosthodontic applications.

When an implant-borne prostheses is delivered through the digital workflow, the exact same two options mentioned above for the tooth-borne FDP are likely. In the best knowledge of the authors, the is no report of the clinical adjustments needed for the first and second options mentioned above neither for tooth- nor implant-borne FDP; or studies that evaluate the accuracy of the additive manufactured definitive casts for both toothand implant-borne FDP.

Revilla-León et al37 analysed the position accuracy of implant analog on 3D printed polymer versus conventional dental stone casts measured using a coordinate measuring machine (CMM). Additive manufacturing technologies evaluated were capable to duplicate conventional definitive implant cast with the same accuracy than conventional procedures. 
The development of the digital systems allows the manufacturing of complete dentures (CD) through CAD-CAM procedures38-47 where a denture base can be milled or both the denture base and the denture teeth can be mill in one piece. $41,42,45,46$

Maeda et al41 was the first scientific report in English where CAD-CAM technique was described to fabricate a $\mathrm{CD}$. The digitalization of the conventional impression is completed and followed by the $\mathrm{CAD}$ design of the $\mathrm{CD}$. The manufacturing of the denture base or the whole CD was described by either a milling process or a SLA 3D printer.

Sun et al47 described a technique that combine analogic and digital procedures where the individual flasks were fabricated using AM technologies. The digitalization of the conventional working edentulous maxillary and mandibular casts, wax rims and maxillomandiular record was completed with an extraoral scanner. A software was developed by the authors, which was used to set-up the denture teeth, to design the artificial gingiva, the base plate and the virtual flasks.

In 2015, Bilgin et al48 also described a combination of conventional and digital procedures where the DLP AM technology was used to fabricate the denture teeth in one piece with a micro-hybrid nano-filled resin. Similarly than previous authors, the digitalization of the working edentulous plaster casts mounted on the articulator and the wax rims was obtained using a laboratory dental scanner.

Inokoshi et al49 compared the teeth try-in for a maxillary and mandibular CD obtained from conventional and AM technologies on ten patients. By conventional procedures, a base plate and denture teeth wax-up was prepared and digitalized using a CBCT. A complete denture teeth try-in design was completed using a CAD software and manufactured using a polyjet 3D printer. According to patient ratings, both techniques were evaluated equally in terms of aesthetics, predictability of final denture shape, stability, comfort of the dentures and overall satisfaction. However, from the 
prosthodontists rating, chair time was, try-in stability and overall satisfaction were significantly higher with the AM than with the conventional method.

When manufacturing a $\mathrm{CD}$, a complete digital workflow would include the digital impression of the completely edentulous arch that includes challenging areas for the intraoral devices like the registration of mobile areas as the non-queratinized tissue or smooth surfaces covered by saliva.39,40 Pazelt et al39 developed an in-vitro study which aim was to analyse the capability of the intraoral scanners to reproduce accurately edentulous arches. The authors concluded that these digital impressions appear to be feasible, although the accuracy of the scanners differs significantly. The results of this study showed that only one scanner was sufficiently accurate to reproduce the edentulous jaw. However, the master edentulous cast used on this in-vitro study is a silicone model that may not represent precisely the clinical oral conditions.

The systematic review of Brida et al,44 concluded that the use of computer-aided technology to fabricate CD has been studied since 1994 by multiple investigators using $\mathrm{CAD} / \mathrm{CAM}$ as well as rapid prototyping methods. Significant advancements in this technology have been made since its inception, but currently no clinical trials or clinical reports are available in the scientific literature.

\section{Printed castable patterns}

There are multiple available castable polymers for the different 3D printing technologies (Fig. 8B) which can be process through conventional procedures and thus, obtained casted metal or pressed lithium disilicate restorations.50-60

Williams et al50 reported the fist dental CAD-CAM clinical case description for fabricating a castable 3D printed pattern for a metal framework of a removable partial denture (RPD). The digitalization of the master cast was completed with an extraoral 
scanner, the undercuts were electronically identified on surveyed virtual cast and the digital design of the RPD was done with a CAD software. The castable pattern was casted through conventional procedures. Later, a technique for the $\mathrm{CoCr}$ RPD framework manufacturing using metal AM technologies was reported.51,52

Kattadiyil et al,54 in a case report article, described a technique that combine analogic and digital procedures for the RPD fabrication. The digital impression was made with an intraoral scanning device (iTero, Cadent) to obtain the virtual master cast, a total of 56 scans were needed to capture the maxillary and mandibular arches and the interoclusal record and another 25 scans for the rests seats. The framework of the RPD was created using a CAD software and manufactured additively. The RPD was finished using the conventional procedures.

A castable printed pattern can be also used to manufacture pressed lithium disilicate ceramic restorations. However, on the best knowledge of the authors, only few studies evaluated the marginal and internal fit considering the fabrication method of the patterns (handmade, milled or printed). Fathi et al58 measured the internal and marginal gap of the crowns fabricated from handmade, milled and AM patterns using the replica and sectioning technique. The restorations presented with a clinically acceptable marginal gap between $111 \pm 28 \mu \mathrm{m}$ and $126 \pm 43 \mu \mathrm{m}$, furthermore the crown obtained from a $3 \mathrm{D}$ printed pattern showed a significant better marginal and internal gap in both measurement techniques.

Mai et al59 analyzed the marginal and internal gap and the accuracy of the proximal contact of the crowns fabricated from three different manufacturing processes: compression molding, milling and 3D PP technology (Object Eden, Stratasys). The fit was evaluated with the silicone-replica and the image superimposition techniques. No differences were found on the proximal point obtained between the 3 techniques, however 
the compression molding technique also presented specimens with a deficient proximal contact. The smallest absolute marginal gap was obtained on the 3D PP group $(99 \pm 19$ $\mu \mathrm{m})$ and the highest was for the molding group $(163 \pm 86 \mu \mathrm{m})$. Moreover, the 3D PP group presented a better internal gap, being at the occlusal measurement the most evident.

Kim et al60 evaluated the reproducibility and marginal discrepancy of resin copings fabricated using a SLA printer by repeating 1,3, or 6 arrays to give a total number of 18 .

\section{Custom impression trays}

Custom trays can be also manufactured through AM technologies (Fig. 8CD).61,62 The CAD design of the custom tray allows the control of a homogeneous space for the impression material and reduces the manual procedures. In the best knowledge of the authors, it has been reported the fabrication of $3 \mathrm{D}$ printed custom trays for a completely edentulous patient59 and for a complete arch implant impression technique.61 Nevertheless, this manufacturing process can be used in any clinical procedure where a custom tray is needed.

\section{FUTURE PRESPECTIVES AND CONCLUDING REMARKS}

The integration and development of protocols for a complete digital workflow are still needed. A promising future is ahead for the prosthodontic applications of the AM technologies, where a complete digital workflow could be systematically applied on our daily work.

The continuous development and improvement of the AM technologies are unstoppable as well as the variety of materials that can be printed. The future is challenging our dental needs. The main challenge, in the opinion of the authors, could be 
to face the rapid obsolescence of the new technologies that needed an important economical investment for the dental laboratories and private practices, the complete digital integration that requires a different methodologies caused by the different tools where a learning curve is needed and the resistance to change when incorporating new processes because of the command of the conventional ones.

\section{Conflict of Interest}

The authors did not have any commercial interest in any of the materials used in this study. 


\section{TABLES}

Table 1: Summary of some of the available AM printers available on the market for dental applications.

\begin{tabular}{|c|c|c|c|c|c|}
\hline BRAND & TECHNOLOGY & PRINTER & LIGHT SOURCE & $\begin{array}{c}\text { Min. LAYER } \\
\text { THICKNESS }(\mu \mathrm{m})\end{array}$ & RESOLUTION (xyz) \\
\hline \multirow{5}{*}{ 3D systems } & SLA & ProJet 1200 & UV Laser & 30 & $56 \mu \mathrm{m}(\mathrm{XY}), 585 \mathrm{DPI}$ \\
\hline & \multirow{3}{*}{ MultiJet } & \multirow{3}{*}{ ProJet MJP 3600 Dental } & \multirow{3}{*}{ UV Laser } & \multirow{3}{*}{$29-32$} & *UHD: 750x750x890 DPI \\
\hline & & & & & *HDX: 375x450x790 DPI \\
\hline & & & & & *HDP: $375 \times 450 \times 790$ DPI \\
\hline & SLA & ProJet $6000 \mathrm{MP}$ & UV Laser & $50-100$ & $4000 \mathrm{DPI}$ \\
\hline \multirow{3}{*}{ BEGO } & \multirow{2}{*}{ SLA } & Varseo & UV Bulb (405 nm) & $50-100$ & $50 \mu \mathrm{m}(\mathrm{XY})$ \\
\hline & & Varseo L & UV Bulb (405 nm) & $50-100$ & $60 \mu \mathrm{m}(\mathrm{XY})$ \\
\hline & DLP & Varseo S & UV LED (405 nm) & $50-100$ & $60 \mu \mathrm{m}(\mathrm{XY})$ \\
\hline DREVE & DLP & $* * \mathrm{NA}$ & UV LED & $* * N A$ & $* * N A$ \\
\hline \multirow[b]{3}{*}{ Envisiontec } & \multirow{3}{*}{ SLA } & VIDA & UV LED HD 1080x1920 & $25-150$ & $73 \mu \mathrm{m}(\mathrm{xy}), 25-150 \mu \mathrm{m}(\mathrm{z})$ \\
\hline & & VIDA Hi-Res & UV LED HD 1080x1920 & $50-150$ & $50 \mu \mathrm{m}(\mathrm{xy}), 50-150 \mu \mathrm{m}(\mathrm{z})$ \\
\hline & & $\begin{array}{l}\text { VIDA Hi-Res } \\
\text { Crown-Bridge } \\
\end{array}$ & UV LED HD 1080x1920 & $25-150$ & $35 \mu \mathrm{m}(\mathrm{xy}), 25-150 \mu \mathrm{m}(\mathrm{z})$ \\
\hline \multirow{2}{*}{ Formlabs } & \multirow{2}{*}{ SLA } & Form1+ & UV Laser $405 \mathrm{~nm}, 120 \mathrm{~mW}$ & $25,50,100,200$ & NA \\
\hline & & Form2 & UV Laser 405nm, 250mW & $25,50,100,200$ & $150 \mu \mathrm{m}(\mathrm{XY})$ \\
\hline \multirow{2}{*}{ RapidShape } & \multirow{2}{*}{ DLP (385nm) } & D30 & UV LED HD 1080x1920 & $35,50,100$ & $29 \mu \mathrm{m}(\mathrm{XY})$ \\
\hline & & D40 & UV LED HD 1080x1920 & $35,50,100$ & $29 \mu \mathrm{m}(\mathrm{XY})$ \\
\hline \multirow{4}{*}{ Stratasys } & \multirow{4}{*}{ PolyJet } & Object30 OrthoDesk & UV Bul (200-400nm) & 30 & 600x600x900 DPI \\
\hline & & Object260/500 Dental & UV Bul (200-400nm) & 16,28 & \multirow{3}{*}{$\begin{array}{l}{ }^{*} \mathrm{HQ}: 600 \times 600 \times 1600 \mathrm{DPI} \\
{ }^{*} \mathrm{HS}: 600 \times 600 \times 907 \mathrm{DPI}\end{array}$} \\
\hline & & Object30 Dental Prime & UV Bul (200-400nm) & 16,28 & \\
\hline & & ObjectEden 260VS & UV Bul (200-400nm) & 16,28 & \\
\hline
\end{tabular}

*UHD: Utra-high definition, HDX: High-definition smooth, HDP: High-definition plaster; HQ: High quality, HS: High speed. **NA: Not available 
Table 2: Summary of some of the material available for AM printers, approved for dental applications.

\begin{tabular}{|c|c|c|c|}
\hline BRAND & NAME & DEFINITION PROVIDED & $\begin{array}{l}\text { WAVELENGTH } \\
(\mathbf{n m})\end{array}$ \\
\hline \multirow{12}{*}{ 3D systems } & VisiJet FTX Green & Tough Castable plastic & \multirow{12}{*}{405} \\
\hline & VisiJet FTX Cast & Wax and plastic hybrid & \\
\hline & VisiJet M3 DentCast & Wax-up castable material & \\
\hline & VisiJet FTX Cast & Wax-up castable material & \\
\hline & VisiJet FTX Green & Wax-up castable material & \\
\hline & VisiJet M3 PearlStone & Solid Stone appereance & \\
\hline & VisiJet M3 StonePlast & $\begin{array}{l}\text { USP Class IV capable, } \\
\text { translucent or stone finish }\end{array}$ & \\
\hline & VisiJet M2R-TN & Models, Tan color & \\
\hline & VisiJet SLe-Stone & High-Contrast color, dental stone & \\
\hline & VisiJet SL Clear & $\begin{array}{l}\text { USP Class VI capable, crystal- } \\
\text { clear appearance, polycarbonate- } \\
\text { like }\end{array}$ & \\
\hline & Accura e-Stone & High-contrast color, dental stone & \\
\hline & Accura ClearBlue & $\begin{array}{l}\text { USP Class VI capable, crystal- } \\
\text { clear appearance, polycarbonate- } \\
\text { like }\end{array}$ & \\
\hline \multirow{5}{*}{ BEGO } & VarseoWax Splint & Occlusal splint, clear & \multirow{5}{*}{405} \\
\hline & VarseoWax SG & Surg. Guide, transparent blue & \\
\hline & VarseoWax CAD/Cast & Castable, opaque yellow & \\
\hline & VarseoWax Tray & Custom trays, opaque blue & \\
\hline & VarseoWax Model & Model, yellow-brown & \\
\hline \multirow{5}{*}{ DeltaMed } & 3Delta Model & Models, apricot color & \multirow{5}{*}{$385-405$} \\
\hline & 3Delta Model Ortho & Orthodontic devices, beige color & \\
\hline & 3Delta Cast & Castable, brown color & \\
\hline & 3Delta Cast P & Castable, orange color & \\
\hline & 3Delta Guide & Surgical guides & \\
\hline \multirow{7}{*}{ Detax } & Freeprint cast & Castable, red color & \multirow{7}{*}{$\begin{array}{c}\text { LED UV } 405 \\
\text { or } \\
378-388\end{array}$} \\
\hline & Freeprint tray & Custom impression trays & \\
\hline & Freeprint splint & Splints, surgical guides & \\
\hline & Freeprint Temp & $\begin{array}{l}\text { Provisional restorations. Color } \\
\mathrm{A} 1, \mathrm{~A} 2, \mathrm{~A} 3\end{array}$ & \\
\hline & Freeprint model & Models. Color: ivory, grey, sand & \\
\hline & Freeprint model T & $\begin{array}{l}\text { Models for the thermoforming } \\
\text { technique. Color: light blue }\end{array}$ & \\
\hline & Freeprint ortho & Orthodontic devices. Color: Clear & \\
\hline \multirow{4}{*}{ Dreve } & FotoDent Model & Model, opaque beige & \multirow{4}{*}{405} \\
\hline & FotoDent Tray & Custom impression trays & \\
\hline & FotoDent Guide & Surgical guides & \\
\hline & FotoDent Gingiva & Gingiva for models & \\
\hline \multirow{7}{*}{ Envisiontec } & E-aapliance/3SP/M & Ortho appliances & \multirow{7}{*}{$365-405$} \\
\hline & $3 \mathrm{SP}$ & Models, peach & \\
\hline & Ortho Tough 3SP/M & Ortho models aligners, pink & \\
\hline & E-DentStone/M & Models & \\
\hline & ClearGuide/M & Surgical guides, clear & \\
\hline & E-Guard & Occlusal splints, clear & \\
\hline & E-Partial & Castable, RPD & \\
\hline
\end{tabular}




\begin{tabular}{|c|c|c|c|}
\hline & E-Dent/M & $\begin{array}{l}\text { Microfilled provisionals. Color } \\
\text { A1, A2, A3 }\end{array}$ & \\
\hline & Press-E-Cast/M & Castable, yellow & \\
\hline \multirow{5}{*}{ FormLabs } & Dental SG & Surgical Guides, clear & \multirow{5}{*}{405} \\
\hline & Dental Model & Models & \\
\hline & Dental LT Clear & $\begin{array}{l}\text { Splints, retainers or orthodontic } \\
\text { devices }\end{array}$ & \\
\hline & Castable & Castable & \\
\hline & Grey Resin & Models, trays & \\
\hline \multirow{12}{*}{ Nexdent } & Base & Denture Base, pink & \multirow{12}{*}{$\begin{array}{c}\text { Blue UV-A } \\
(315-400) \\
+ \\
\text { UV-Blue } \\
(400-550)\end{array}$} \\
\hline & SG & Surgical Guide, transparent & \\
\hline & $\mathrm{C} \& \mathrm{~B}$ & Crowns \& Bridge, class IIa & \\
\hline & C\&B MFH & $\begin{array}{l}\text { C\&B Micro filled hybrid, class } \\
\text { IIa }\end{array}$ & \\
\hline & Ortho Clear & Splint \& retainers, class IIa & \\
\hline & Ortho IBT & Ortho applications, class I & \\
\hline & Ortho Rigid & Splints, class IIa & \\
\hline & Model & Dental models, oker & \\
\hline & Model Ortho & Dental models, beige & \\
\hline & Tray & Tray, class I, blue and pink & \\
\hline & Gingiva Mask & Gingiva mask models, Pink & \\
\hline & Cast & Castable material, purple & \\
\hline \multirow[b]{2}{*}{ Shera } & SheraPrint gingiva mask & Gingiva masks for models & \multirow[b]{2}{*}{ NA } \\
\hline & SheraPrint & $\begin{array}{l}\text { Models, splints, trays, surgical } \\
\text { guides }\end{array}$ & \\
\hline \multirow{4}{*}{ Stratasys } & Clear-Bio (MED610) & Clear biocompatible & \multirow{4}{*}{$200-400$} \\
\hline & VeroGlaze (MED620) & A2 color, provisional up to $24 \mathrm{~h}$ & \\
\hline & VeroDent (MED670) & Models & \\
\hline & $\begin{array}{l}\text { VeroDent Plus } \\
\text { (MED690) }\end{array}$ & Models & \\
\hline
\end{tabular}

*NA: Not available. 


\section{REFERENCES}

1. ASTM, Committee F42 on Additive Manufacturing Technologies, West Conshohocken, Pa. Standard terminology for additive manufacturing - general principles and terminology. ISO/ASTM52900-15, 2009.

2. Hull CW. Apparatus for production of three-dimensional objects by stereolithography, US Patent 4575330, 1986.

3. Hull CW, Spence ST, Albert DJ, Smalley DR, Harlow RA, Steinbaugh P, Tarnoff HL, Nguyen HD, Lewis CW, Vorgitch TJ, Remba DZ. Method and apparatus for production of three-dimensional objects by stereolithography, US Patent 5059359, 1991.

4. Hull CW, Spence ST, Albert DJ, Smalley DR, Harlow RA, Stinebaugh P, Tarnoff HL, Nguyen HD, Lewis CW, Vorgitch TJ, Remba DZ. Method and apparatus for production of high resolution three-dimensional objects by stereolithography, US Patent 5184307, 1993.

5. André JC, Cabrera M, Jezequel JY, Méhauté A. French Patent 2583333, 1985.

6. André JC, Méhauté A, Witthe O. Dispositif pour realiser un module de piece industrielle, French Patent 8411241, 1984.

7. Stansbury JW, Idacavage MJ. 3D printing with polymers: Challenges among expanding options and opportunities. Dent Mater 2016;32:54-64.

8. Liska R, Schuster M, Infuhr R, Tureeek C, Fritscher C, Seidl B, Schmidt V, Kuna L, Haase A, Varga F, Lichtenegger H, Stampfl J. Photopolymers for rapid prototyping. J Coatings Technol Res 2007;4:505-10. 
9. Infuehr R, Pucher N, Heller C, Lichtenegger H, Liska R, Schmidt V, Kuna L, Haase A, Stampfl J. Functional polymers by two-photon 3D lithography. Appl Surface Sci 2007;254:836-40.

10. Reeves P. Additive Manufacturing - A supply chain wide response to economic uncertainty and environmental sustainability. Econolyst Limited, The Silversmiths, Derbyshire, UK. 2009. p. 12-45.

11. Petrovic V, Gonzalez JVH, Ferrando OJ, Gordillo JD, Puchades JRB, Grinan LP. Additive layered manufacturing: sectors of industrial application shown through case studies. Int J Prod Res 2011;49:1061-79.

12. Hornbeck L. Digital Micromirror Device. US Patent No. 5.061.049. 2009.

13. Groth C, Kravitz ND, Jones PE, Graham JW, Redmond WR. Three-dimensional printing technology. J Clin Orthod 2014;48:475-85.

14. Bartolo PJ. Stereolithography: Materials, Processes and Applications. Ed. Springer, 2011. p. 1-32.

15. Singh V. Rapid Prototyping, Materials for RP and Applications of RP. Int J Eng Res Sci 2013;4:473-80.

16. Fahad M, Dickens P, Gilbert M. Novel polymeric support materials for jetting based additive manufacturing processes. Rapid Prototyp J 2013;19:230-9.

17. Miller FP, Vandome AF, McBrewster J. Fused deposition modelling. VDM Publishing 2010. p. 13-34.

18. Van Nort R. The future of dental devices is digital. Dent Mater 2012;28:3-12.

19. Gibson I, Rosen DW, Stucker B. Additive Manufacturing Technologies: Rapid Prototyping to Direct Digital Manufacturing. Ed. Springer, New York, NY. 2010. p. 63-103. 
20. Chua CK. Rapid prototyping: Principles and applications. 3rd Ed. World Scientific Publishing Co. Pte. Ltd. 2010. p. 35-135.

21. Krar S, Gill A. Exploring Advanced Manufacturing Technology. New York, Industrial Press Inc. 2003. p. 7-2-1.

22. Allen S, Dutta D. On the computation of part orientation using support structures in layered manufacturing. Proceedings of the Solid Freeform Fabrication Symposium, Austin, TX. 1994. p. 259-69.

23. Puebla K, Arcaute K, Quintana R, Wicker RB. Effects of environmental conditions, aging, and build orientations on the mechanical properties of ASTM type I specimens manufactured via stereolithography. Rapid Prototyp J 2012;18:374-88.

24. Alharbi N, Osman R, Wismeijer D. Effect of build direction on the mechanical properties of 3D printed complete coverage interim dental restorations. J Prosthet Dent 2016;155:760-7.

25. Brain M, Jimbo R, Wennenberg A. Production tolerance of additive manufactured polymeric objects for clinical applications. Dent Mater 2016;32:853-61.

26. Ide Y, Nayar S, Logan H, Gallagher B, Wolfaardt J. The effect of the angle of acuteness of additive manufactured models and the direction of printing on the dimensional fidelity: clinical implications. Odontology 2017;105:108-15.

27. Plooji JM, Maal TJ, Haers P, Borstlap WA, Kuijpers-Jagtman AM, Berge SJ. Digital three-dimensional image fusion processes for planning and evaluating orthodontics and orthognathic surgery. A systematic review. Int J Maxillofac Surg 2011;40:34152.

28. Rossini G, Parrini S, Castroflorio T, Deregibus A, Debernardi CL. Diagnostic accuracy and measurement sensitivity of digital models for orthodontic purposes: A systematic review. Am J Orthod Dentofacial Orthop 2016;149:161-70. 
29. Pachêcho-Pereira C, De Luca Canto G, Major PW, Flores-Mir C. Variation of orthodontic treatment decision-making based on dental model type: A systematic review. Angle Orthod 2015;85:501-09.

30. De Luca Cant G, Pachêcho-Pereira C, Lagravere MO, Flores-Mir C, Major PW. Intra-arch dimensional measurement validity of laser-scanned digital dental models compared with the original plaster models: a systematic review. Orthod Craniofac Res 2015;18:65-76.

31. Aragón ML, Pontes LF, Bichara LM, Flores-Mir C, Normando D. Validity and reliability of intraoral scanners compared to conventional gypsum models measurements: a systematic review. Eur J Orthod 2016;38:429-34.

32. Ender A, Mehl A. Accuracy of complete-arch dental impressions: A new method of measuring trueness and precision. J Prosthet Dent 2013;109:121-8.

33. Patzelt SB, Bishti S, Stampf S, Att W. Accuracy of computer-aided design/computeraided manufacturing-generated dental casts based on intraoral scanner data. J Am Dent Assoc 2014;145:1133-40.

34. Saleh WK, Ariffin E, Sherriff M, Bister D. Accuracy and reproducibility of linear measurements of resin, plaster, digital and printed study-models. J Orthod 2015;42:301-6.

35. Hazeveld A, Huddleston Slater JJ, Ren Y. Accuracy and reproducibility of dental replica models reconstructed by different rapid prototyping techniques. Am J Orthod Dentofacial Orthop 2014;145:108-15.

36. Murugesan K, Anandapandian PA, Sharma SK, Vasantha Kumar M. Comparative Evaluation of Dimension and Surface Detail Accuracy of Models Produced by Three Different Rapid Prototype Techniques. J Indian Prosthodont Soc 2012;12:16-20. 
37. Revilla-León M, Gonzalez-Martín O, Pérez López J, Sánchez-Rubio JL, Özcan M. Position accuracy of impant analogs on 3D printed polymer versus conventional dental stone casts measured using a coordinate measuring machine. J Prosthodont $2017 ; 00: 1-8$

38. Patzelt SB, Vonau S, Stampf S, Att W. Assessing the feasibility and accuracy of digitizing edentulous jaws. J Am Dent Assoc 2013;144:914-20.

39. Matsuda T, Goto T, Yagi K, Kashiwabara T, Ichikawa T. Part-Digitizing System of Impression and Interocclusal Record for Complete Denture Fabrication. J Prosthodont 2016;25:503-9.

40. Maeda Y, Minoura M, Tsutsumi S, Okada M, Nokubi T. A CAD/CAM system for removable denture. Part I: Fabrication of complete dentures. Int J Prosthodont $1994 ; 7: 17-21$.

41. Kawahata N, Ono H, Nishi Y, Hamano T, Nagaoka E. Trial of duplication procedure for complete dentures by CAD/CAM. J Oral Rehabil 1997;24:540-8.

42. Goodacre CJ, Garbacea A, Naylor WP, Daher T, Marchack CB, Lowry J. CAD/CAM fabricated complete dentures: concepts and clinical methods of obtaining required morphological data. J Prosthet Dent 2012;107:34-46.

43. Bidra AS, Taylor TD, Agar JR. Computer-aided technology for fabricating complete dentures: systematic review of historical background, current status, and future perspectives. J Prosthet Dent 2013;109:361-6.

44. Infante L, Yilmaz B, McGlumphy E, Finger I. Fabricating complete dentures with CAD/CAM technology. J Prosthet Dent 2014;111:351-5.

45. Wimmer T, Gallus K, Eichberg M, Stawarczyk B. Complete denture fabrication supported by CAD/CAM. J Prosthet Dent 2016;115:541-546. 
46. Sun Y, Lu P, Wang Y. Study on CAD\&RP for removable complete denture. Comput Methods Programs Biomed 2009;93:266-72.

47. Bilgin MS, Erdem A, Aglarci OS, Dilber E. Fabricating complete dentures with CAD/CAM and RP technologies. J Prosthodont 2015;24:576-9.

48. Inokoshi M, Kanazawa M, Minakuchi S. Evaluation of a complete denture trial method applying rapid prototyping. Dent Mater J 2012;31:40-6.

49. Williams RJ, Bibb R, Rafik T. A technique for fabricating patterns for removable partial denture frameworks using digitized casts and electronic surveying. J Prosthet Dent 2004;91:85-88.

50. Williams RJ, Bibb R, Eggbeer D, Collis J. Use of CAD/CAM technology to fabricate a removable partial denture framework. J Prosthet Dent 2006;96:96-99.

51. Williams RJ, Eggbeer D, Bibb R. CAD/CAM rapid manufacturing techniques in the fabrication of removable partial denture frameworks. Quintessence J Dent Technol 2008;6:42-50.

52. Wu M, Tinschert J, Augthum M, Wagner I, Schädlich-Stubenrauch J, Sahm PR, Spiekermann H. Application of laser measuring, numerical simulation and rapid prototyping to titanium dental castings. Dent Mater 2001;17:102-108.

53. Kattadiyil MT, Mursic Z, AlRumaih H, Goodacre CJ. Intraoral scanning of hard and soft tissues for partial removable dental prosthesis fabrication. J Prosthet Dent 2014;112:444-8.

54. Lin WS, Chou JC, Metz MJ, Harris BT, Morton D. Use of intraoral digital scanning for a CAD/CAM-fabricated milled bar and superstructure framework for an implantsupported, removable complete dental prosthesis. J Prosthet Dent 2015;113:509-15.

55. Torabi K, Farjood E, Hamedani S. Rapid Prototyping Technologies and their Applications in Prosthodontics, a Review of Literature. J Dent 2015;16:1-9. 
56. Cho SH, Chang WG. Mirror-image anterior crown fabrication with computer-aided design and rapid prototyping technology: A clinical report. J Prosthet Dent 2013;109:75-8.

57. Fathi H, Al-Masoody A, El-Ghezawi N, Johnson A. The accuracy of fit crowns made from wax patterns produced conventionally (hand formed) and via CAD/CAM technology. Eur J Prosthodont Restor Dent 2016;24:10-7.

58. Mai HN, Lee KB, Lee DH. Fit of interim crowns fabricated using photopolymerjetting 3D printing. J Prosthet Dent 2016;118:208-15.

59. Kim DY, Jeon JH, Kim JH, Kim HY, Kim WC. Reproducibility of different arrangement of resin copings by dental microstereolithography: Evaluating the marginal discrepancy of resin copings. J Prosthet Dent 2017: 117:260-265.

60. Revilla-León M, Sánchez-Rubio JL, Özcan M. Impression technique for complete arch with multiple implants using additive manufacturing technologies. J Prosthet Dent 2017;117:714-720.

61. Chen H, Yang X, Chen L, Wang Y, Sun Y. Application of FDM three-dimensional printing technology in the digital manufacture of custom edentulous mandible trays. Sci Rep 2016;14:19207. 


\section{FIGURES}

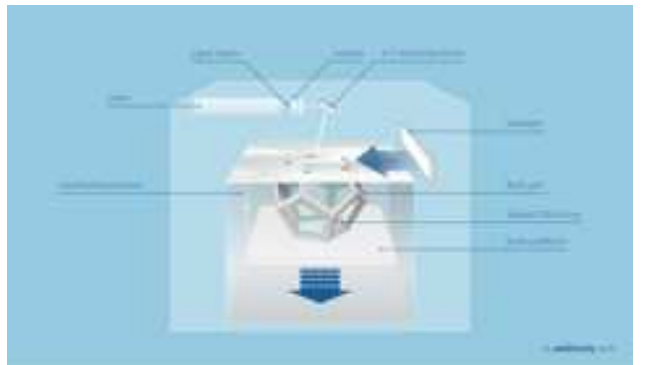

Fig. 1AB. A, Stereolithography AM technology scheme. Illustration courtesy of Additively.com.

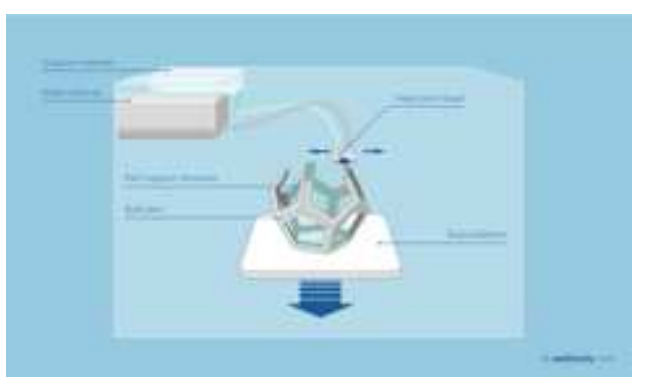

Fig. 2. Material jetting 3D printing technology scheme. Illustration courtesy of Additively.com.

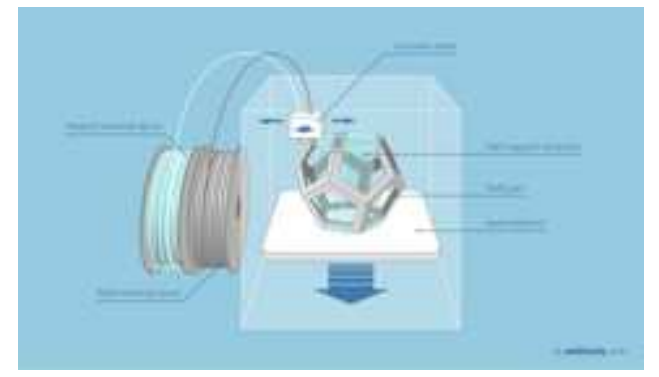

Fig. 3. Material extrusion or fused deposition modelling additive manufacturing technology scheme. Illustration courtesy of Additively.com.

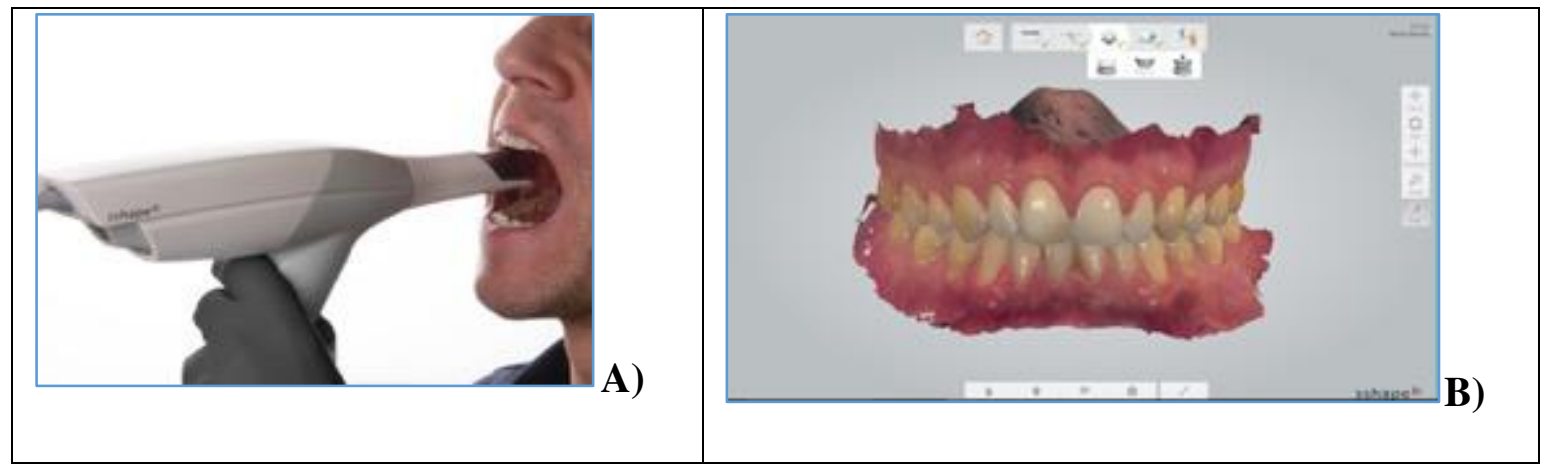


Figs. 4AB. A, Data acquisition with an intraoral scanner device (TRIOS 3 Color Pod, 3Shape); and B, Digital impression of the maxillary, mandibular and interocclusal record completed with the intraoral scanner device. A Data Mining Extensions (DMX) file is created.

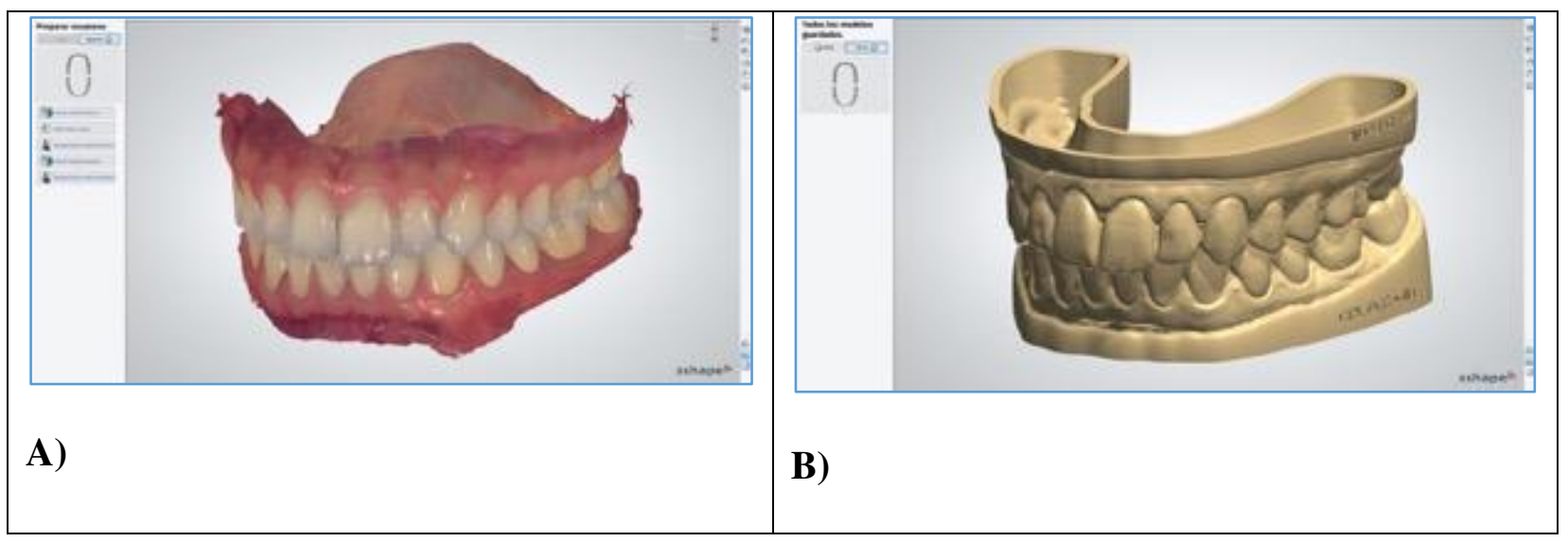

Figs. 5AB. Data processing example from the data acquisition with an intraoral scanner to the virtual design of the diagnostic models. A, The DMX file created from the digital impression is imported into the specific CAD software (Dental System, 3Shape); and B, Specific dental CAD software (Model Builder, Dental Systems, 3Shape) was used to create the STL file of a virtual maxillary and mandibular models.

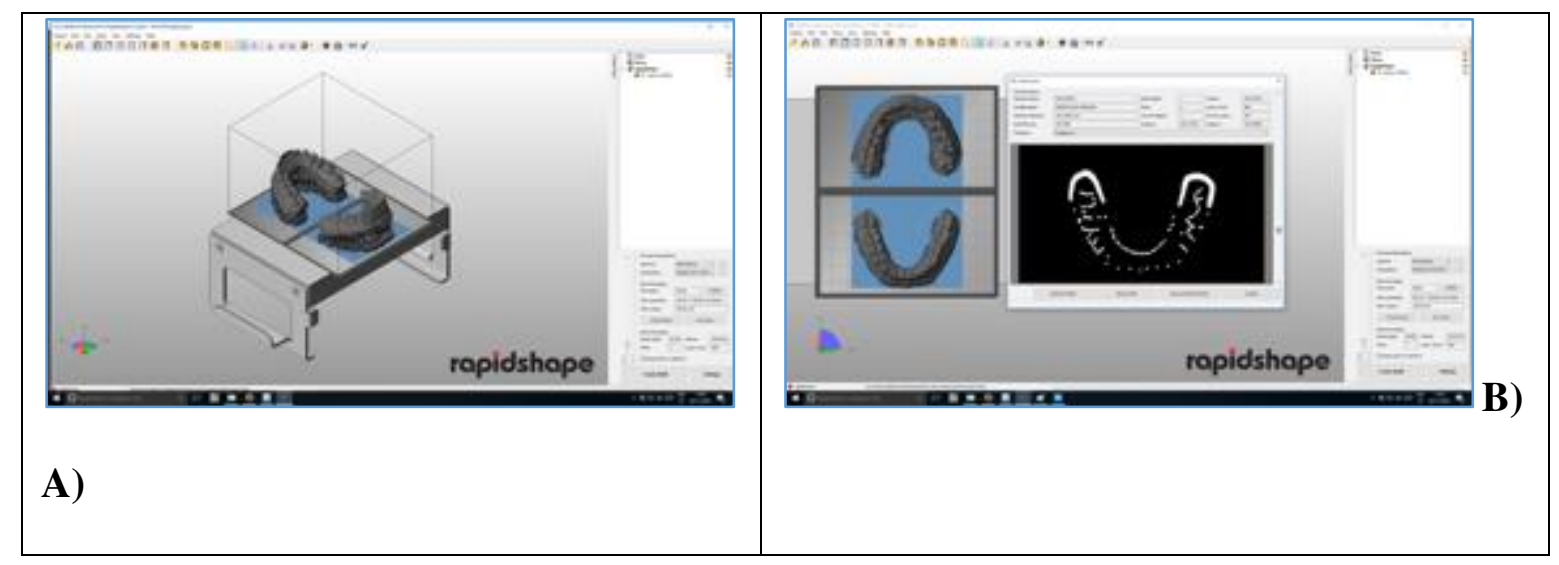


Figs. 6AB. Data processing by the specific printer software (D30 RapidShape, RapidShape) for the objects. A, Positioning and orientation on the building platform and; B, Slicing, adding the supportive structures and volume calculation of the polymer resin needed.

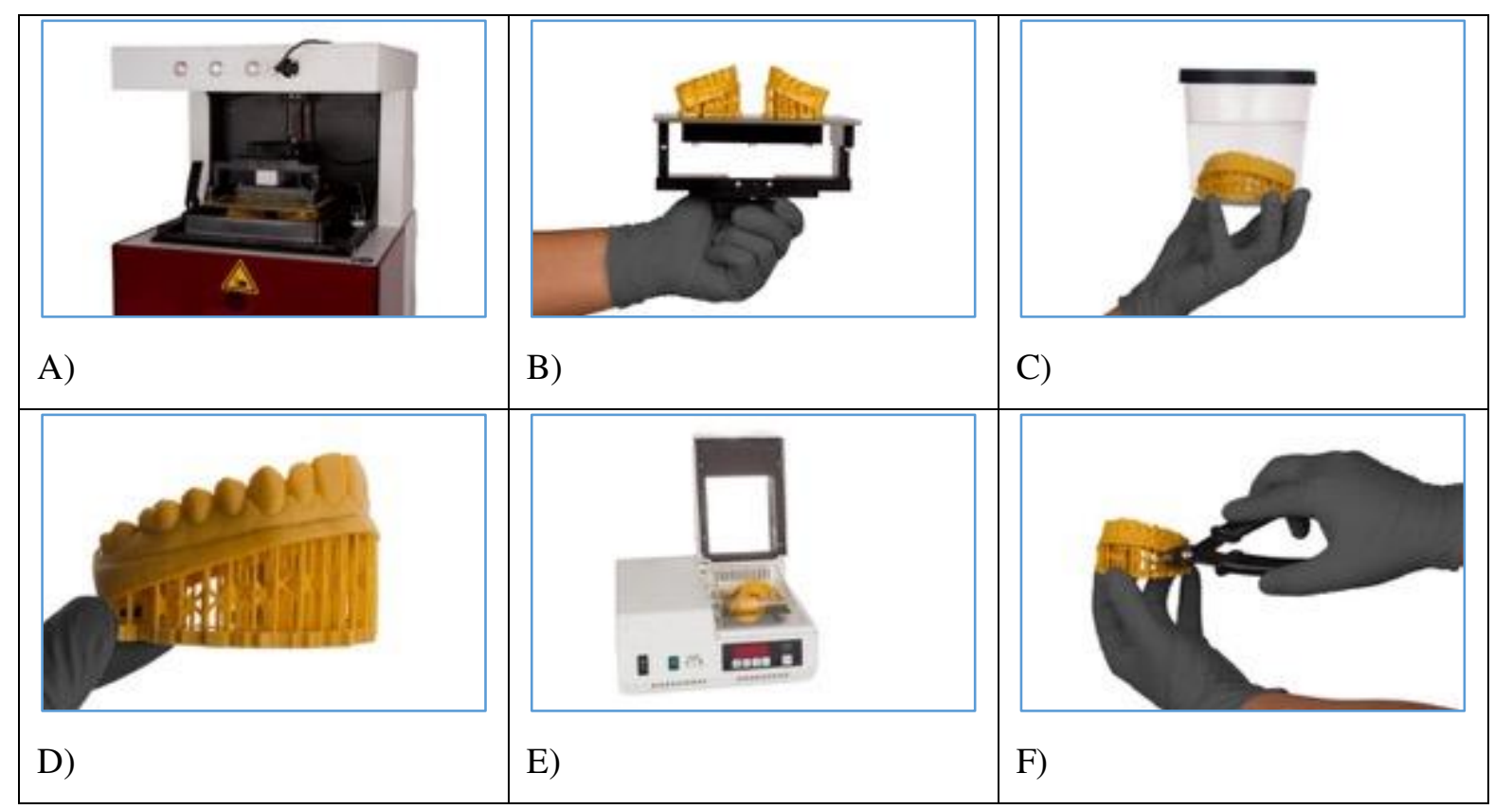

Figs. 7A-F. Example of the additive manufacturing process using a DLP printer (D30 RapidShape, RapidShape). A, DLP printer manufacturing dental models; B, Building platform with the AM casts just printed; $\mathrm{C}$, after the removal of the printed objects of the building tray, the AM objects are submerged on an cleaning solution (Isopropyl 96\%) during 4 minutes in order to remove the non-polymerized resin; D, The models are placed inside a UV-light lamp (Otoflash, BEGO) to complete the light cure of the AM model; and, E, Removal of the supportive structures.

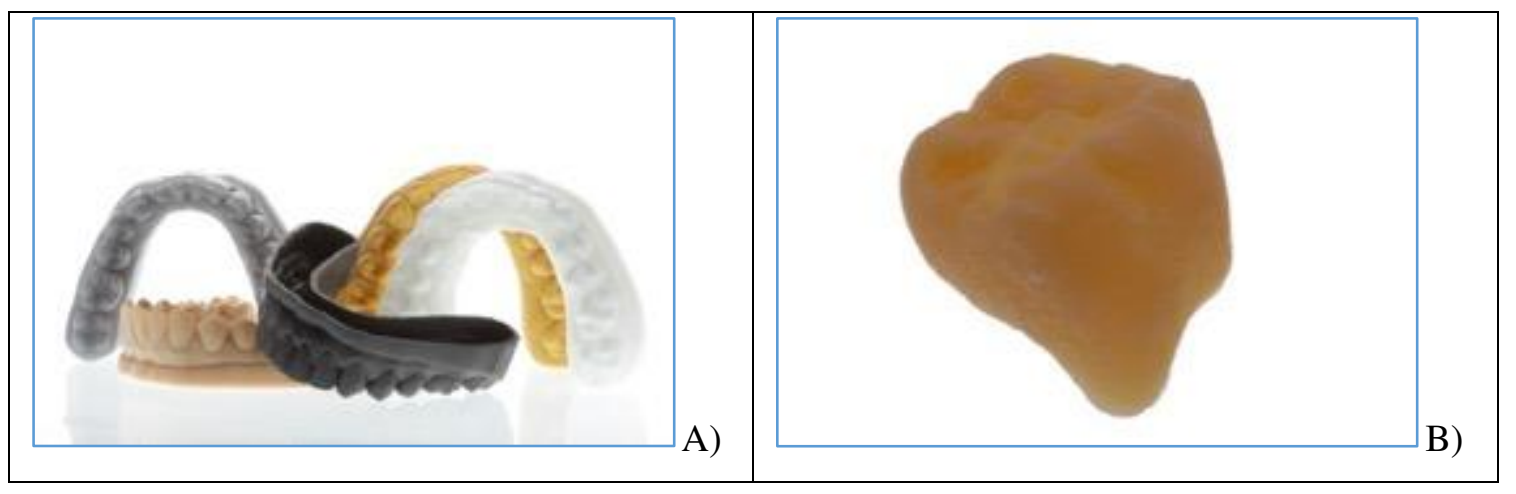




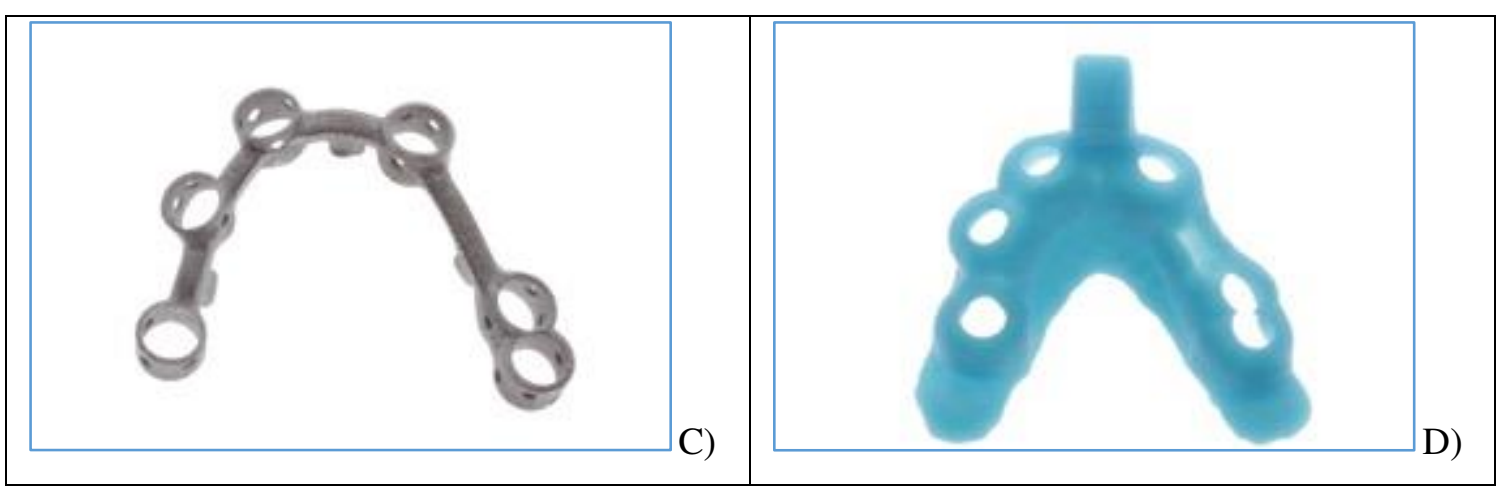

Figs. 8A-D Examples of different applications of polymers AM technologies for dentistry; A, AM dental casts fabricated with different technologies and polymers; B, 3D printed castable pattern of a full coverage restoration; C, 3D printed metal framework for a complete arch implant impression; and D) AM custom tray for a complete arch open tray implant impression. 